\title{
Review: Utilization of yeast of Saccharomyces cerevisiae origin in artificially raised calves
}

\author{
Gibson M. Alugongo, Jianxin Xiao, Zhaohai Wu, Shengli Li, Yajing Wang and Zhijun Cao*
}

\begin{abstract}
Yeast of Saccharomyces cerevisiae (SCY) origin has over long time been incorporated into domestic animal diets. In calves, several products have offered improved performance and health. Although several types of research have been completed, the mode of action of SCY is not clear in calves. Under this review, we have highlighted the works available in the literature on the use of SCY in calves performance, health, immunity, and the gut environment. Both active live yeast and yeast culture have positive effects on growth, rumen, small intestines, immunity and general health of the calf. Specifically, SCY can improve DMl, growth, feed efficiency and reduce diarrhea in calves. Furthermore, subtle improvements are seen in rumen fermentation (increased butyrate production) and rumen papillae growth. These positive results are, however, more pronounced in calves that are under stress or exposed to significant levels of disease-causing agents. There is a need for further research in areas such as gut morphology, gut microbiology and immunity using latest molecular methods to fully understand how SCY helps the growth and development of calves.
\end{abstract}

Keywords: Active live yeast, Calves, Health, Yeast culture

\section{Background}

Improved management and nutrition can promote optimal growth, better feed efficiency and health in young calves [1]. On the other hand, low growth rates can result in underweight at weaning and further post-weaning growth which cannot be compensated through future nutrition [2]. Furthermore, for a sustainable and profitable enterprise the costs of raising replacement heifers and age at first calving should be lower [3, 4]. Extensive research related to calves feeds and feeding is available in literature $[5,6]$. Despite the progress made over the past decades, animal nutritionists continue to investigate how different dietary components support the growth and well-being of animals. Research is further moving from general responses to diet such as dry matter intake (DMI), growth and fecal scores to specific areas such as metabolic changes and gut microbiota [7]. For example, Lactobacilli and Bifidobacteria populations are an important component of a balanced microbiota in the gut [8];

\footnotetext{
* Correspondence: caozhijun@cau.edu.cn

State Key Laboratory of Animal Nutrition, Department of Animal

Nutrition and Feed Sciences, China Agricultural University, Beijing,

People's Republic of China
}

however, stress conditions may result in their decreased number hence setting in the pathogenic micro-organisms. Diarrhea, is a leading cause of death in calves (more than $62 \%$ of mortality in dairy calves' industry; [9]), arises from the abundance of pathogenic micro-organisms such as Enterotoxigenic Escherichia coli (ETEC) and Salmonella in the small intestine which releases enterotoxins into the gut lumen.

Feed additives are usually used on the farm to improve the performance of young animals [3]. The utilization of antibiotics has offered some of these benefits over many years in calves. However, use of antibiotics in livestock production has become a sensitive issue due to the reported cases of antibiotic resistance to pathogens in humans and calves supplemented with antibiotics in milk $[10,11]$. Moreover, there is growing concern held by consumers over their effects on human health $[12,13]$. Probiotics and prebiotics have been seen as the best alternative to antibiotic use in young animals [14].

Yeast of Saccharomyces cerevisiae (SCY) origin has over long time been incorporated into domestic animal diets [15]. Dairy and beef cattle, pigs, horses, sheep and 
their young ones, have all shown improved performance when fed SCY as compared to those not fed [16-18]. In mature ruminants $[19,20]$ both active live yeast (ALY) and yeast culture (YC), have reported improved nutrient utilization, altered rumen fermentation and enhanced production parameters [21-23]. Originally, works on growing animals that were exposed to transport stress showed better growth and health when offered SCY products [24]. Recently, research on the utilization and function of SCY products have been gaining extensive interest in calf nutrition $[25,26]$.

To the best of our knowledge, no effort has been made to summarize the work that exists in the literature on feeding SCY in calves. Therefore, the purpose of this paper is to highlight the advances that have been made in feeding both ALY and YC and try to point out areas of research that can be exploited to add to the available knowledge and help in the further understanding of how SCY improves calves' performance and health. Some of the discussions incorporate other animal models, due to the paucity of information on studies in calves and with the view that some of the principals can be applied to calves. This review has utilized fully published research as well as research published in abstract form and available online. Our discussion is further limited to only products that contain ALY or YC but where applicable, references have been made to research on products that are derived from Saccharomyces cerevisiae.

\section{Differences in active live yeast and yeast culture}

Yeast of Saccharomyces cerevisiae origin has been extensively researched on both in-vitro and in vivo [27] to determine its effect in animal models. There are various ALY and YC products from S. cerevisiae yeast available on the market. The products are classified based on the active ingredients and their modes of action [20]. Two broad groups exist in the literature depending on the viability of cells in the product. Active live yeast products are fermentable living yeasts that have been dried and contain at least $15 \times 10^{9}$ live yeast cells per gram while a $\mathrm{YC}$ is produced through fermenting cereal grains in a selected liquid with bakers yeast then drying the whole medium culture [20, 27]. The YC contents may include yeast cell wall ( $\beta$-glucans and mannanoligosaccharides), cell solubles, vitamins, proteins, peptides, amino acids, nucleotides, lipids, organic acids, esters and alcohols, B vitamins, polyphenols, organic acids and anti-oxidants $[28,29]$ all of which may have positive effects on performance and health when incorporated into the diet of animals. The composition of each of the above bioactive compounds in SCY have not been characterized [30] and as a result, the effects of SCY are mostly attributed to the yeast wall components. Any efforts that would be made to characterize the quantity of the mentioned components would make it comparatively easy while explaining the molecular or physiological changes that are observed in calves.

The active live yeast is considered to offer mainly probiotic effect while the yeast culture components are regarded as having both probiotic and prebiotic effect. Fuller [31] defined probiotics as live microbial supplements that beneficially affects the health and well-being of the host animal by improving its gastrointestinal balance. Recent research has shown that the two products might not have significant differences in their mode of action on rumen fermentation [27].

\section{Effects of SCY on calf feed intake, growth, feed efficiency}

Saccharomyces cerevisiae yeast products have the ability to stimulate starter intake in calves (Table 1). However, the impact of feeding SCY on DMI in calves has not been consistent. Experiments have reported different performances both before and after weaning. Some researchers have reported significantly higher intakes pre-weaning [32, 33] while others did not observe any significant changes [34]. Others observed positive effects of SCY on DMI post-weaning only [35]. Several of the papers retrieved reported no differences in DMI whether in the pre-weaning or post-weaning period [36-39]. Different factors such as the strain of yeast, the nature of the diet or the physiological status of the animal [40], dose and feeding strategy $[35,41]$ influence DMI. The high DMI reported in Harris et al. [26], Galvao et al. [32], and Lesmeister et al. [35], respectively, happened during periods of the high incidence of diarrhea and abrupt weaning respectively. Using 512 animals, Magalhães et al. [41] found no significant differences between treatment and control groups in both preand post-weaning periods. These authors attributed the results to less starter intake in the first 21d of the life of the calf which is very crucial period. In older transition dairy cows, Zaworski et al. [17] have suggested that YC can improve dietary energy utilization or absorption that may be dependent or independent of DMI.

Average daily gain (ADG) is directly related to DMI. With higher DMI, it is likely that the ADG will also be higher (Table 1). However, similar to the lack of changes in DMI in most researches, ADG was not significantly different except for few experiments that had significantly higher ADG post-weaning [35, 39], which were concomitant with DMI. It is, however, possible to have periods of higher ADG in SCY supplemented calves as was observed in a recent research where calves were infected with Citrobacter freundii on $16 \mathrm{~d}$ of the study [26]. The calves that were supplemented with SCY showed higher ADG during $15 \mathrm{~d}-21 \mathrm{~d}$ and also had lower fecal scores during the same period. This implies that calves might have been protected from the adverse 
Table 1 Showing effects of Saccharomyces cerevisiae Yeast (SCY) products in calves performance

\begin{tabular}{|c|c|c|c|c|c|c|c|c|c|c|c|c|}
\hline \multirow[t]{3}{*}{ S/No } & \multirow[t]{3}{*}{ Study } & \multirow{3}{*}{$\begin{array}{l}\text { No. of } \\
\text { Calves }\end{array}$} & \multirow[t]{3}{*}{ Period, $d$} & \multicolumn{9}{|c|}{ Parameters } \\
\hline & & & & \multicolumn{3}{|c|}{$\mathrm{ADG}^{1}$} & \multicolumn{3}{|c|}{$\mathrm{DMl}^{2}, \mathrm{~kg}$} & \multicolumn{3}{|l|}{$\mathrm{FE}^{3}$} \\
\hline & & & & CON & $\mathrm{SC} 1$ & SC2 & $\mathrm{CON}$ & SC1 & SC2 & CON & SC1 & $\mathrm{SC} 2$ \\
\hline \multirow[t]{3}{*}{1} & Lesmeister, et al. [35] & 75 & $0-35$ & 0.38 & 0.36 & 0.42 & 0.28 & 0.29 & 0.32 & 2.73 & 2.90 & 2.71 \\
\hline & & & $35-42$ & $0.74^{\mathrm{a}}$ & $0.92^{\mathrm{b}}$ & $0.94^{\mathrm{b}}$ & $1.33^{\mathrm{a}}$ & $1.42^{\mathrm{ab}}$ & $1.54^{\mathrm{b}}$ & 2.33 & 1.95 & 1.67 \\
\hline & & & $0-42$ & $0.44^{\mathrm{a}}$ & $0.44^{\mathrm{ab}}$ & $0.51^{b}$ & $0.48^{\mathrm{a}}$ & $0.51^{\mathrm{ab}}$ & $0.56^{\mathrm{b}}$ & 2.25 & 2.25 & 2.00 \\
\hline \multirow[t]{2}{*}{2} & Galvao et al. [32] & 52 & $5-42$ & 0.30 & 0.47 & & $0.44^{\mathrm{a}}$ & $0.68^{b}$ & & $0.27^{\mathrm{a}}$ & $0.40^{\mathrm{b}}$ & \\
\hline & & & $43-84$ & 0.91 & 1.04 & & $2.19^{\mathrm{a}}$ & $2.58^{\mathrm{b}}$ & & 0.43 & 0.43 & \\
\hline \multirow[t]{3}{*}{3} & Quigley, et al. [34] & 42 & $1-42$ & 0.18 & 0.17 & & 0.21 & 0.24 & & 0.30 & 0.27 & \\
\hline & & & $43-84$ & 0.48 & 0.51 & & 1.47 & 1.52 & & 0.31 & 0.32 & \\
\hline & & & $1-84$ & 0.33 & 0.43 & & 0.84 & 0.88 & & 0.30 & 0.30 & \\
\hline \multirow[t]{3}{*}{4} & Magalhães, et al. [41] & 512 & $4-28$ & 0.23 & 0.20 & & 0.15 & 0.13 & & 1.50 & 1.22 & \\
\hline & & & $29-70$ & 0.78 & 0.77 & & 1.43 & 1.41 & & 0.56 & 0.57 & \\
\hline & & & $4-70$ & / & / & & 0.92 & 0.90 & & / & / & \\
\hline 5 & Panda et al. [39] & 12 & $1-91$ & $0.34^{\mathrm{a}}$ & $0.48^{\mathrm{b}}$ & & 512 & 581 & & $3.12^{\mathrm{a}}$ & $2.49^{b}$ & \\
\hline 6 & Harris, et al. [26] & 60 & $0-35$ & $0.48^{\mathrm{a}}$ & $0.48^{\mathrm{a}}$ & $0.58^{b}$ & $0.18^{\mathrm{a}}$ & $0.22^{\mathrm{ab}}$ & $0.25^{\mathrm{b}}$ & & & \\
\hline 7 & Hill, et al. [44] & 116 & $3-63$ & 0.51 & 0.54 & & 0.86 & 0.81 & & 0.70 & 0.66 & \\
\hline 8 & Zhou ${ }^{4}$ et al. [45] & 18 & $1-63$ & $0.31^{\mathrm{a}}$ & $0.52^{\mathrm{ab}}$ & $0.66^{\mathrm{b}}$ & 1.01 & 0.95 & 1.01 & & & \\
\hline 9 & Seymour, et al. [38] & 42 & $1-46$ & 0.46 & 0.43 & & 1.04 & 0.97 & & 2.48 & 2.55 & \\
\hline \multirow[t]{3}{*}{10} & Brewer $^{5}$ et al. [25] & 40 & $0-14$ & 5.3 & 5.5 & & / & / & & / & I & \\
\hline & & & $15-35$ & $10.9^{\mathrm{a}}$ & $17.4^{\mathrm{b}}$ & & / & / & & / & / & \\
\hline & & & $0-35$ & $16.7^{\mathrm{a}}$ & $23.8^{\mathrm{b}}$ & & / & / & & / & / & \\
\hline 11 & Yan et al. [53] & 12 & $1-60$ & $0.52^{\mathrm{a}}$ & $0.66^{\mathrm{b}}$ & & $0.95^{\mathrm{a}}$ & $1.08^{b}$ & & / & / & \\
\hline 12 & Hučko, et al. [37] & 30 & $4-56$ & 0.384 & 0.381 & & 0.61 & 0.62 & & 2.63 & 2.96 & \\
\hline 13 & Hoseinabadi ${ }^{6}$, et al. [80] & 30 & $13-65$ & 0.67 & 0.67 & 0.65 & $1.22^{\mathrm{a}}$ & $1.00^{\mathrm{b}}$ & $1.15^{\mathrm{ab}}$ & 0.39 & 0.44 & 0.41 \\
\hline 14 & Pinos-Rodriguez, et al. [33] & 16 & $4-60$ & / & / & & $0.84^{\mathrm{a}}$ & $0.91^{b}$ & & 3.46 & 3.51 & \\
\hline 15 & Huuskonen and Pesonen [36] & 40 & $20-75$ & 0.82 & 0.76 & & 0.69 & 0.67 & & 3.26 & 2.21 & \\
\hline \multirow[t]{3}{*}{16} & Kaldmäe, et al. [87] & 20 & $6-35$ & 0.38 & 0.35 & & 1.25 & 1.22 & & 3.26 & 3.51 & \\
\hline & & & $36-65$ & 0.99 & 1.03 & & 2.29 & 2.33 & & 2.30 & 2.25 & \\
\hline & & & $6-65$ & 0.69 & 0.69 & & / & / & & / & I & \\
\hline
\end{tabular}

CON Saccharomyces cerevisiae Yeast (SCY) in milk or starter, SC1 Saccharomyces cerevisiae Yeast (SCY) at level 1 unless stated otherwise, SC2 Saccharomyces cerevisiae Yeast $(\mathrm{SCY})$ at level 2 unless stated otherwise

${ }^{\mathrm{a}, \mathrm{b}}$ Significantly different $(P<0.05)$

$A D G^{1}$ Average Daily Gain

$D M I^{2}$ Dry Matter Intake

$F E^{3}$ Feed Efficiency (DMI/ADG; DMI does not include milk or milk replacer intake)

Zhou ${ }^{4}$ included CON, Starter + hay and Starter + SCY respectively

Brewer ${ }^{5}$ instead of ADG he reported the total body weight gain

Hoseinabadi ${ }^{6}$ included $\mathrm{CON}, \mathrm{SCY}$ in starter and $\mathrm{SCY}$ in milk, respectively

effects of diarrhea in that window of the period. In an experiment carried out on Yea-Sacc 1026, in calves averaging $54 \mathrm{~kg}$ at the beginning of the experiment, calves that had been supplemented with $0.0625 \%$ and $0.125 \%$ of the concentrate diet gained only $5 \mathrm{~kg}$ more than the unsupplemented group at the end of $84 \mathrm{~d}$ experiment [42]. No differences have been observed in feed efficiency for calves fed YC $[35,41]$ probably due to the lack of significant differences in the DMI and ADG in the experiments that reported on FE. In an experiment with an ALY, Panda et al. [39] showed that cross-bred calves without supplementation had a lower feed to gain ratio compared to supplemented group. In lambs, Haddad and Goussous [43] indicated that YC had an effect on body weight, growth and feed to gain ratio though no differences were observed in DMI.

Occasionally, body weight and body structure measurements have also been reported. Hill et al. [44] did not observe any changes in height and heart girth. However Zhou et al. [45] reported that YC improved the height and 
withers width in calves. Similarly, we did not observe any changes in calves' withers height, length, heart girth and hip width [46]. The structural changes reported by Zhou et al. [45] could be linked to increase in energy intake and protein as a result of significant increase in digestibility of nutrients. Some authors have argued that SCY can cause an increase in energy and other nutrients intake [35].

Metabolic responses are valuable in providing information on the nutritional status of the animal. For example, glucose and BHBA are good indicators of energy metabolism in calves. However, SCY does not seem to have an effect on blood parameters of calves except for one experiment that showed that a live yeast product can increase glucose concentration [32, 41].

\section{Effect of SCY on selected health parameters}

A calf in good health will have high growth rates and hence better future performance. Calves are very susceptible to diseases caused by various pathogens and environmental stressors in the first months of their lives since their immune system is still naive. Similarly, the weaning process might be very stressful, leading to increased respiratory problems in calves. Low growth rates due to disease can result in poor weaning weight and further post-weaning growth which cannot be compensated through future nutrition [2]. The farmer needs a veritable security against a potential outbreak of gastrointestinal and respiratory diseases which are common in the first couple of months.

The most reported health effects of SCY have been on either the reduction of diarrhea and improvement of fecal scores (Table 2; [32, 38, 41]). In some studies, no effect on health parameters was reported [35]. The reasons for inconsistency in response to supplementation have only been speculated in most of the trials conducted. In an experiment working with 512 calves, $12.1 \%$ and $7.5 \%$ of control and YC treatment calves died respectively [41]. However, the risk of death was similar before d 13 but 6-fold more among control group afterward. The authors attributed the observations in first two weeks to the low feed intake during this period as the YC was added in calf starter only. In another experiment, effects of anti-Salmonella by Saccharomyces cerevisiae fermentation product (SCFP), a YC, were investigated by adding the products to milk replacer and starter grain [25]. The calves were fed two weeks before and three weeks after experimental challenge with Salmonella enterica serotype Typhimurium. Calves were monitored for clinical signs and parameters associated with Salmonellosis after the challenge. Calves that were supplemented with SCFP showed fewer bouts of diarrhea and fever. In the control group, Salmonella shedding could be seen $4 \mathrm{~d}$ after shedding in the treatment group had stopped. Galvao et al. [32] observed reduced number of days with diarrhea, but the fecal scores were similar to the treatment and control. To investigate whether there were differences between pre- and post-weaning, supplementing an ALY in the feed resulted in a positive effect on the health of the calves before weaning [38]. The positive results observed with SCY in the trials above could be dependent on the level of pathogenicity, the housing conditions, feeding regimes and environmental factors among others.

The complex stable microbial flora present in the gut helps the animal to resist infections [31]. Modern trends in conditions used to rear animals can disrupt the natural condition that exists in the gut hence interference with animal performance [31]. In young calves, when the pathogenic (such as coliform and lactic acid bacteria) bacteria proliferate in the small intestines, bacterial diversity is interfered with and subsequently reduction in commensal bacteria may arise [47]. Since the decrease in microbial diversity in the first month has been associated with diarrhea incidences in calves [48] could feeding SCY help improve its microbial diversity? Yeast culture metabolites possess the ability to inhibit pathogenic flora while supporting the commensal bacteria in vitro [49]. This could be a major factor in clearing the gut lumen of pathogenic bacteria and hence supporting

Table 2 The health parameters affected by yeast products in calves

\begin{tabular}{|c|c|c|c|c|}
\hline \multirow[t]{2}{*}{ No. } & \multirow[t]{2}{*}{ Parameter } & \multicolumn{3}{|c|}{ Response to SCY supplementation } \\
\hline & & Increased & Similar & Reduced \\
\hline 1. & Diarrhea & & {$[33,34,38]$} & {$[25,32,35,37,41,47,63,80]$} \\
\hline 2. & Fever & & {$[38,44]$} & {$[36]$} \\
\hline 3. & Respiratory infections & & {$[34,38,44]$} & \\
\hline 4. & Use of antibiotics & & & {$[41,44]$} \\
\hline 5. & Use of electrolytes & & {$[50]$} & \\
\hline 6. & Immune responses & & & {$[41]$} \\
\hline \multirow[t]{2}{*}{7.} & Mortality & & & {$[41]$} \\
\hline & Medication costs & & {$[50]$} & {$[44]$} \\
\hline 8. & Others (e.g. bloat, cough) & & [41] & \\
\hline
\end{tabular}


the commensal bacteria which are important in the process of carbohydrates fermentation that result in higher volatile fatty acids [25]. In large intestines, YC increased the microbial species richness and stimulated the fibrolytic bacteria (Ruminococcaceae) colonization, which increased butyrate subsequently lowered diarrhea incidences [46, 50].

Body temperature is an important parameter in diarrheic calves. Fever is usually observed in calves with the very loose fecal matter. Hill et al. [44] observed lower temperatures in Jersey's calves with a tendency towards significance for calves that had been supplemented with an AYC while Seymour et al. [38] reported significantly lower temperatures for Holstein calves supplemented with YC. Most of the observations were based on a judgment by the eyes for example assigning of fecal scores which are subjective to the person involved in the recording the scores.

Since diarrhea is closely associated with loss of electrolytes, several experiments have shown that yeast products can lead to decreased use of electrolytes in calves $[41,50]$. Although the reduction in the use of electrolytes has been reported based on the quantity used more research should be done to determine how SCY reduce losses of electrolytes and reduce dehydration in calves. The intestinal epithelium is the first protective barrier from exogenous pathogens [51]. Calves might have a compromised intestinal permeability even before being given colostrum which subsequently predisposes the calf to higher diarrhea rates even when they have achieved passive transfer of immunity [52].

Calf diarrhea is also an expensive venture in terms of time and labor costs spent on therapy. The SCY can reduce calf raising costs $[41,53]$ mainly through lower costs on medications. This is especially important on farms with high antibiotic use as evidenced by reduced days of antibiotic therapy in morbid calves and lambs $[50,54,55]$ and labor costs. The product is cheap and can be used throughout the growth period with less addition on calf raising costs [41]. Yan et al. [53] observed that it cost less to raise calves supplemented with a YC $(20 \mathrm{~g} / \mathrm{d})$ by up to $29.98 \%$ in a $60-\mathrm{d}$ experiment. Another advantage of YC is that it can be used in combination with other additives such as ionophores and antibiotics and still be efficacious $[56,57]$.

Most of the scientists argue that yeast products might be more efficient when animals have been challenged by disease or stressful environment such as weaning stress or when they have been offered high-concentrate diets [40]. In Quigley et al. [34] experiment they concluded that effects of YC on calves was masked by high incidences of disease in calves. While this might have been true, then it is important to note that the SCY products are also evolving with a better understanding on how they may be offering benefits in animals. The extent of stressors and disease might be one of the determinants of the outcome of a test of SCY in calf health [40]. Lack of statistical differences in fecal scores as indicated by Lesmeister et al. [35] is paradoxical but might be as a result of how diarrhea rate was calculated in their experiment or the causal agent of diarrhea in this calves.

\section{Effect of SCY on calf immunity}

The gut provides the site for nutrients absorption and is also the first line of defense against pathogens and other harmful substances for the animal [17]. It remains as the main anatomical location that SCY might play a significant role in immunomodulation. Several complex polysaccharides found in the yeast cell wall such as $\beta$ glucans and mannan-oligosaccharides have been identified as the modulators of immunity [29]. The in vitro experiment by Jensen et al. [49] showed that a YC product could provide anti-oxidant, anti-inflammatory and immuno-modulatory activities. Since then, several experiments have been carried out in calves [26], lambs [58] and piglets $[59,60]$ to determine the efficacy of these SCY products in vivo. Magalhães et al. [41] tried to test some measures of the innate immune system in vivo and found no influence of feeding YC product in calves. Anti-OVA IgG concentrations and phagocytic activity of non-pathogenic $E$. coli were similar between control and YC treated groups. They, however, observed a slight increase in phagocytic activity of neutrophils when cells were incubated with pathogenic E. coli. The authors concluded that oligosaccharides present in YC could have enhanced the neutrophils phagocytic activity. However, the mechanism by which the oligosaccharides, in this case, $\beta$-glucans stimulated the immune system were not reported. For immunomodulatory effect, $\beta$-glucans have to move from the lumen and interact with the immune cells. It has been suggested that cells of $S$. cerevisiae yeast cannot penetrate the intestinal endothelium barrier while only pure $\beta$-glucan have immunomodulatory effects [61]. Therefore, it is likely that the whole yeast cell might not stimulate the immune system, but either $\beta$-glucan fragments or other alternative mechanisms are involved.

The yeast cell wall's $\beta$-glucans component are identified as pathogen-associated molecular patterns (PAMPs) by the pattern recognition receptors (PRR) in the lumen [62] since the animal body can neither synthesize them nor are they part of its body. The innate immune system components such as neutrophils, macrophages and natural killer (NK) cells are involved in this response [62]. Recently, Harris, et al. [26] reported a treatment and a time interaction in neutrophil to lymphocytes ratio (NLR) in calves infected with Citrobacter freundii and a lower NLR in calves supplemented with a YC (Fig. 1). Similar results have been demonstrated in piglets that 


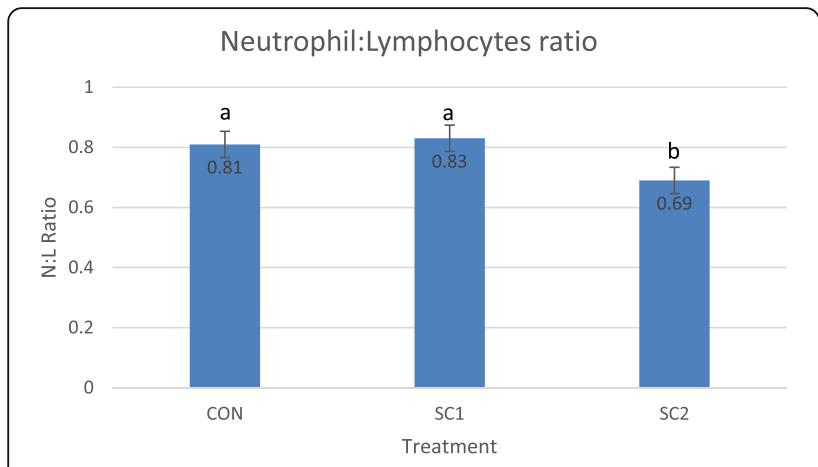

Fig. 1 Effects of SCY on neutrophil: lymphocytes ratio in calves. CON: No Saccharomyces cerevisiae Yeast (SCY) in milk or starter; SC1: Saccharomyces cerevisiae Yeast (SCY) in milk only; SC2: Saccharomyces cerevisiae Yeast (SCY) in milk and starter. ${ }^{a, b}$ Significantly different $(P<0.05)$. Adapted from Harris et al. [26]

had been exposed to weaning and transport stressors [60]. A trial with either healthy or calves infected with an endotoxin and fed with an AYC showed that calves that had been supplemented recovered quickly from the effects of endotoxin compared to the unsupplemented group [63]. When calves are exposed to an endotoxin, they will show clinical signs as a result of changes in hematology such as leukocytes count [64] and in behavioral changes such as those of feed intake, lying or standing time, self-grooming and rumination [65]. Wang et al. [63] results are indicative of the capacity of YC to ameliorate effects of endotoxemia in calves through immunoregulation. Alternatively, the advantage of SCY could come through activation of the adaptive immune responses that require to be activated and proliferate to reach a critical mass that can deal with infectious agents. It also requires to generate effector mechanisms that are most suited to eliminate the infection and this also takes time.

Lack of systemic changes may explain the difficulty in observing the changes in immune parameters [30]. This might be explained by the "dampened" feedback mechanism in the in vivo immune responses that protect the host against excessive inflammatory responses [62]. Moreover, modulation of the immune responses does not lead to excess stimulation or suppression of the immune activity [66]. Immune responses in pre-ruminant calves could also be more dependent on the plane of nutrition. Some researchers have suggested that improved health in calves is based on improved supply of nutrients rather than changes in components of the immune system $[67,68]$. In others, neutrophil responses were shown to be higher in calves that received low plane of nutrition compared to the higher plane of nutrition $[69,70]$. When taken together, these results suggest that for SCY to be more potent, the animals should be under a certain degree of stress that demands more energy from the animal, which might not have been the case in most of the reported experiments.
Immunological and anti-oxidation systems are mutually complementary mechanisms. In an in vitro study with yeast culture product, Jensen et al. [29] have shown that $\mathrm{YC}$ at the lowest level $(0.0001 \mathrm{mg} / \mathrm{L})$ can significantly reduce the formation of reactive oxygen species (ROS) in polymorphonuclear (PMN) cells. The YC can be important in animals that experience inflammatory responses in the gut due to pathogenic gut microorganisms [41]. Farmers are advised to check whether the calves have received immunity in the first 24-48 h [71] although this might not be practical on all the farms.

\section{Future research}

There is more exciting information that needs to be unraveled on the effect of SCY in calves' health. Future studies should focus studying the establishment of intestinal microbiota in young calves supplemented with SCY to help determine the protective capacity of these products as young calves lack a well-developed and stable intestinal microbiota. Since it has been suggested that the yeast components such as the $\beta$-glucans, nucleotides or small peptides can directly influence the immune system or indirectly by altering the gut environment [30] and might be more potent in young animals [62] more research need to be done in these areas.

The gut absorptive capacity has been linked to the integrity of the epithelium, while SCY has been shown to improve the crypt depth to villus height ratio [46]. More research using xylose absorption test to determine how SCY reduces the loss of electrolytes and hence fewer electrolyte in calves could be adopted. Xylose absorptive test has been recommended for testing absorptive capacity in the small intestines [72].

Experiments should also consider microbiological analyses of fecal matter to determine the infectious agents available in the environment of the study. It is encouraging, however, to note that the positive effects are present throughout the first three months of life of the calf. More controlled and focused work need to be done to decipher how SCY might affect the general health and immunity of calves. Furthermore, the products should be experimented with animals that have not been exposed to disease causing agents in order determine whether the products can have effect on healthy animals.

\section{Effects of SCY on gastrointestinal parameters}

The stomach of a newborn calf is likened to that of a monogastric animal due to its small and nonfunctional rumen. As the calf ages, the gut anatomy and metabolic functions are expected to change. Calves are fed restricted amounts of liquid feed and starter mixtures containing carbohydrates that are rapidly fermented to butyric and propionate acids. Intake of grain has been shown to support rumen development through production of higher 
amounts of butyrate. The gut microbiota of a 1-4 weeks old calf is very different from that of advanced age when the rumen is fully developed [47]. However, depending on how early the calf is introduced to a calf starter, it is likely to develop a population of bacteria by 9 wks that is similar in every aspect to that found in a mature animal within the same environment [73]. Moreover, a growing body of evidence shows that microbial colonization in rumen occurs immediately after birth and some rumen bacteria that are essential for mature rumen function are present as early as $1 \mathrm{~d}$ after birth [74].

A literature search has shown that SCY mostly affects the rumen and its environment in the older ruminants. In their review, Chaucheyras-Durand et al [40] concluded that SCY carried out its functions primarily by altering the rumen microbial populations. These authors noted that the rumen microbiota could be influenced in three ways: 1. Enhancement of rumen maturity through the favoring microbial establishment, 2. Stabilizing ruminal $\mathrm{pH}$ and interactions with lactate-metabolizing bacteria, and 3 . The increase in fiber degradation and interactions with plant cell wall degrading micro-organisms.

In vitro, studies have shown that yeast from Saccharomyces cerevisiae can increase rumen total bacteria, fungi and protozoa [75] or stimulate fungi [76]. The benefits of SCY were more pronounced in diets that had higher fiber content [28]. In young calves, SCY has also been shown to have an effect on gut microbiota and morphological development, though research in this area is still scarce.

\section{Ruminal microbiota composition and fermentation patterns}

From the available studies, there exist contradictory reports on the effect of SCY on ruminal microbial populations and fermentation patterns. While some researchers have indicated that SCY can positively influence ruminal microbiota in young ruminants [77] others have found none in supplemented calves when compared to control groups [47]. Rumen microbiota in calves responds to dietary modifications, structural and physiological changes in the host animal [73]. The total number of bacteria increased in heifers fed SCY [22]. Ciliate protozoa increased in lambs [55]. These experiments might not reflect the changes that happen in the microbiota of young calves since they used samples from older animals or different species respectively, however, they suggest that $\mathrm{SCY}$ might similarly influence the gut microbiota in calves.

Diet composition has an effect on how SCY may affect microbial diversity [22]. In vitro, SCY can stimulate the growth of several bacteria in the rumen, especially lactate utilizing bacteria and those that digest cellulose [28]. In a meta-analysis on feeding an SCY in lactating cows, Robinson and Erasmus [23] proposed that SCY may act by stimulating rumen microbes that increase fermentability of fiber and not by allowing rumen microbes to metabolize more efficiently end-products of ruminal starch fermentation since no impact was noted with increased dietary starch levels. Calf starters are high in grains that have large amounts of starch and lack of reported effects on rumen microbiota might be due to the observations aforementioned. Since the microbial populations in the calves change with age, it would be interesting to investigate the changes that happen with age in rumen microbial flora when calves are fed SCY. ChaucheyrasDurand et al. [40] established that ALY can accelerate microbial diversity in calves which are critical in achieving a functional rumen ecosystem at weaning. Since SCY does not only stimulate bacterial activity in the gut but also change the composition of the bacterial population, current molecular techniques such as high-throughput sequencing can be helpful in identifying those populations influenced by SCY supplementation. In our laboratory, we found out that Firmicutes, Bacteroidetes, and Actinobacteria were predominant throughout the gastrointestinal tract (GIT) of pre-weaned calves, and that bacterial community was highly variable among different GIT sites by using high-throughput sequencing techniques [46]. The inclusion of YC positively affected Butyrivibrio richness (fibrolytic bacteria) in rumen liquid in the first $28 \mathrm{~d}$ and lowered Prevotella on d 28 and d 56 in the supplemented calves which resulted in higher butyrate concentration.

The effect of SCY on rumen volatile fatty acids (VFA) concentration has not been exhaustively studied in preweaning calves. Some researchers have reported decreased total VFA concentration and molar proportion of butyric acid while increasing the molar proportion of acetic acid and the acetate to propionate ratio with live yeast ([37]; Fig. 2). The authors suggested a shift in metabolic activities of ruminal microbiota as a reason for the observed increase in acetate which was attributed to the cellulolytic microbiota. On the other hand, Hill et al. [44] reported no effect in the most important SCFA that is butyrate and propionate in calves that had been supplemented via milk feeding with live yeast at $4 \mathrm{~g} / \mathrm{d}$. However, they reported significant differences in valerate concentration, being higher in yeast supplemented calves (3.71 for CON vs. 5.83 for AYC). Most of the available research has been done among older calves, lambs or cows. Mutsvangwa et al. [78] fed a live yeast culture to 3 months old bulls and they reported an increase in concentrations of acetate and total VFA as a result of YC stimulating rumen fermentation. These bulls received a high concentrate diet of barley grain and soya bean meal and barley straw. Although there may be some similarities in these experiments, diets that were given to older 


\section{Effects of SCY on volatile fatty acids (VFA) in calves}

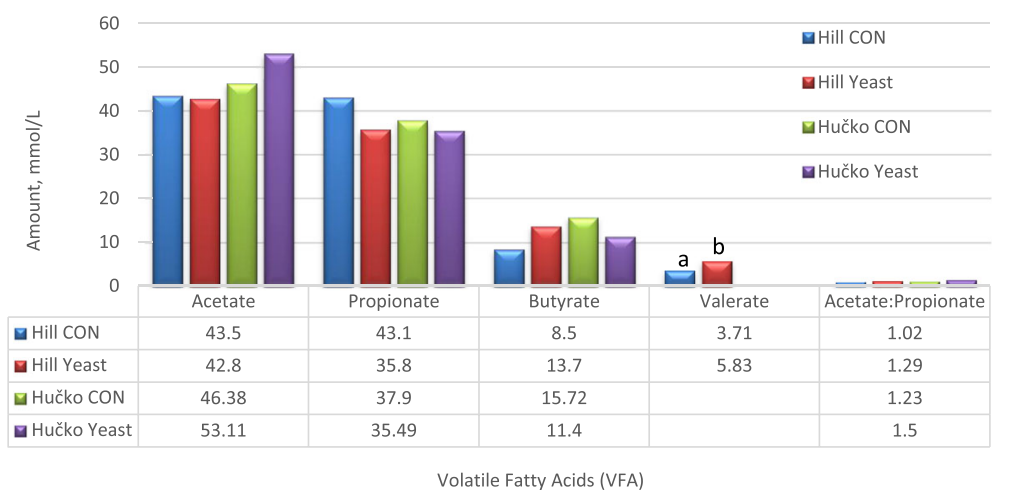

Fig. 2 Effects of SCY on volatile fatty acids (VFA) in calves. CON: Not supplemented with Saccharomyces cerevisiae Yeast (SCY); Yeast: Supplemented with Saccharomyces cerevisiae Yeast (SCY).

a,b Significantly different $(P<0.05)$. Adapted from Hučko et al. [37] and Hill et al. [44]

animals may contain a high amount of fiber [28] thus contributing to the positive effects observed. Tripathi et al. [55] reported decreased the concentration of VFA's in lambs attributing the drop to higher rumen fermentation rate and viable bacterial population after SCY supplementation. The same authors did not confirm the ability of live yeast to scavenge oxygen with reported lack of differences in the establishment of fibrolytic bacteria. The microbiota cellular activity measured by enzymatic profile has shown that yeast culture has an effect on some of the short-chain fatty acids (SCFAs) in young ruminant animals [55].

A stable rumen $\mathrm{pH}$ in a pre-ruminant calf helps provide a suitable environment for a normal functioning of the rumen bacterial and protozoan population [79]. Ruminal $\mathrm{pH}$ can be stabilized through reduced lactate production. Live yeast has been shown to have positive effects on the ruminal parameters of the ruminants [19]. These authors reported that live yeast supplementation led to an increase in ruminal $\mathrm{pH}$ and VFAs concentrations while decreasing lactic acid concentration. In pre-ruminant calves, $\mathrm{pH}$ seems not to be influenced by YC $[46,80]$.

\section{Post-ruminal digestion}

There is very scarce information about the effect of SCY on hindgut digestion in ruminants. Research done in horses fed high starch diet reported similar results to those in ruminants when the horses were fed a live yeast [18]. The lack of information in this section of the animal could be related to the assumption that yeast culture functions mainly in the rumen. However, Durand-Chaucheyras et al. [81] have shown that yeast cells remain alive during the transition in the digestive tract leading to the hypothesis that effects of live yeast may extend beyond the rumen. Recently nutritionists have been trying to offer SCY that bypasses the rumen into the hindgut. Milk drank by the calves, bypasses the rumen and enters directly into the abomasum. Hill et al. [44] supplemented live yeast to the calves in milk at the rate of $4 \mathrm{~g} / \mathrm{d}$.

\section{Ruminal and intestinal structural development}

Understanding both upper and lower gut development is crucial for the improvement of growth and health of the calf. This development depends on the establishment of ruminal flora, initiation of feed consumption, absorption processes and absorption mechanisms [82]. The VFAs especially butyrate are important in triggering rumen papillae growth [83] which provide the surface area for absorption of nutrients. Recently researchers have demonstrated the importance of introducing starter in calves at an early age. Malmuthuge et al. [84] investigated the effect of feeding milk replacer alone or milk replacer with calf starter combined on microbial gut diversity. They were able to show that calf starter in addition to milk replacer resulted in changes in microbial diversity and expression of gene encoding gut barrier function. Earlier, Tajima et al. [85] showed that diet can have significant effect on rumen microbial composition using real-time PCR method. Diet manipulation through feed additives can further enhance the changes in the gut parameters [86]. There is varying information on the effect of SCY on the structural and functional development of the rumen. Supplementation of the YC at $2 \%$ might slightly improve rumen development [35]. These authors observed an increase in papillae length and papillae width at the time of weaning off at 19 and $21 \%$ respectively, though not significantly different. They concluded that the number of calves used and the age at which the observations were made could have contributed to the lack of significant differences. Kaldmäe et al. [87] observed no differences in calves' papillae length and width, rumen 
wall thickness and a number of papillae at either 1 month or 2 months of age. Feeding a YC to calves has been shown to improve rumen papillae maturation [25] in sick calves. However, Magalhães et al. [41] implied that YC has no effect rumen development and function citing similar grain intake and plasma BHBA levels. On the other hand, effects of yeast on rumen are only likely to be observed if the product is fed through a starter and not milk that bypasses the rumen into the abomasum [44]. Work concluded in our research group showed an improvement in rumen papillae and width [46].

Gut development in the first few weeks of calf's life is dynamic and can digest and absorb nutrients [88]. Effect of SCY on the ileal mucosal development in calves has not been reported. However, research in poultry showed that whole yeast cells can influence the villus and villus to crypt depth ratio (VCR) ratio when supplemented in the first $21 \mathrm{~d}$.

It is a probability that $\mathrm{SCY}$ would function more in the hindgut by reducing the infectious agents. Consequently, if it has to be utilized then bypass method, that is, liquid supply would be more efficient. Similarly, calves younger than 3 weeks of age might not consume more yeast through the starter. The changes observed in morphological changes might be observed mainly after the calf starts consuming a significant amount of the starter $[35,46]$. These will be confirmed when rumen development is observed in younger calves such as at 4 weeks of age.

\section{Future research}

Continued research on the effects of nutrients on gut development is paramount to understanding specific calf management strategies that can be put in place to enhance calf gut health and hence performance [89]. Microbial colonization is fundamental for the growth, development and function of the rumen [73] and is dependent on the diet [82]. Some probiotics have been shown to offer protective functions on cell junctions and mucosal barrier damaged by enterotoxigenic E. coli and Salmonella typhimurium infection [90] which we have seen can be ameliorated by SCY [25]. Future research might seek to elucidate how SCY might affect the tight junctions in calves. Due to the complexity of the calves' microbiota focusing on few or individual bacterial species of importance in calves could expedite our understanding of how SCY contributes to calf performance [91]. Similarly, mRNA gene expression could also be used as a tool for changes in crypt depth have been associated with enhanced apoptotic rate [92].

Research should also focus on the influence of SCY on both digesta- and mucosa-associated microbial population and metabolites produced in the GIT. Moreover, we suggest that transcriptomics should be used to elucidate the functional microbial population that might be affected by live yeast and yeast culture supplementation. Making observations over a short period may be helpful in determining at what stage in the life of a calf is $\mathrm{YC}$ more effective on structural parameters.

\section{Suggested mode of action}

Both in-vitro and in vivo experiments have been carried out to define the mechanisms of SCY action in animals [27]. Although the mode of action of the SCY has not been fully elucidated [32] its positive results in young animals are encouraging more research in using calves as models to study its effects. Most of the results have been limited to dry matter intake (DMI), feed efficiency (FE) and fecal scores and antibiotic treatments. However, it seems these positive results might be indirectly or directly related to SCY improving the gut environment by decreasing interaction between pathogens and cells in the gastrointestinal tract of the calves [93] and hence the gut health [32]. Various SCY products have been linked to better rumen fermentation [35].

It remains a challenge for the researchers to conclude definitely what part of both ALY and YC contributes to the positive health benefits or by what mechanisms. Porosity in information on the components that affect the health of calves fed the products have contributed to the speculations. Both proponents of ALY and YC have often pointed out to the presence of isolated components such as $\beta$-glucans and mannan-oligosaccharides [94] contained in the yeast cell wall. The proponents of ALY argue that yeast cell competes with the pathogenic microbes for attachments sites hence inhibiting them from attaching to the gut wall. In poultry, it has been suggested that mannan-oligosaccharides agglutinate to the Type-1 fimbriae structures presented by the pathogenic bacteria hence inhibiting their colonization of the gut lumen [95]. These observations should be applied with caution in calves, since it has been shown that some strains of Enterohemorrhagic Escherichia coli utilize other mechanisms, specifically type III secreted proteins and cytotoxins and not type 1 fimbriae to colonize calves' intestines and cause diarrhea [96]. On the other hand, YC proponents propose that its metabolites are utilized by the gut microbiota leading to reduced number of pathogenic microbiota. To support their case, in vitro research has shown that metabolites produced during the fermentation process of $\mathrm{YC}$ can inhibit pathogenic E. coli growth while stimulating nonpathogenic $E$. coli [49]. It is thought that in vivo the good commensal microbes would utilize the metabolites supplied by the SCFP and through competitive exclusion replace the pathogenic microbes. 
Fewer researchers have focused on how SCY can stimulate an immune response in animals which can help unravel alternative modes of action. However, it is noteworthy that SCY has the potential to assist an animal that is experiencing physiological or environmental stress. The effect of supplementing SCY in calves on growth, performance and health have varied between adding in calf starter, milk or both. The variability in experimental designs might contribute to the differences in results reported. Geographical differences, farm specific pathogens, environmental factors, species and doses applied might all cause the differences in results reported. The rate of supplementation of the different products of SCY also remains to be determined which would further help determine improving the health of the calves.

\section{Conclusions}

Saccharomyces cerevisiae yeast seems to offer benefits to calves through improved DMI, growth, feed efficiency and reduction in diarrhea in calves. Furthermore, subtle improvements are seen in gut related parameters. Specifically, SCY tended to enhance rumen fermentation (increased butyrate production) and rumen papillae growth. However, the merits seem obvious in animals that are under some form of stress. Several questions remain and further studies are required in order to gain a better understanding of the effects of SCY on calves. Areas that could be exploited in future include gut morphology, gut microbiology, and immunity using latest molecular methods like gene expression analysis. Furthermore, standardization of the research protocols needs to be taken into account. More experiments involving same products would result in a better database to carry out a meta-analysis which is considered better in analyzing effects of a product in animal models.

\section{Abbreviations}

ALY: Active live yeast; DMI: Dry matter intake; ETEC: Enterotoxigenic Escherichia coll; FE: Feed efficiency; FPT: Failure of immune transfer; GIT: Gastrointestinal tract; IgG: Immunoglobulin G; NK: Natural killer; NLR: Neutrophil to lymphocytes ratio; PAMPs: Pathogen-associated molecular patterns; PRR: Pattern recognition receptors; ROS: Reactive oxygen species; SCFAs: Short chain fatty acids; SCFP: Saccharomyces cerevisiae fermentation product; SCY: Yeast of Saccharomyces cerevisiae; VCR: Crypt depth ratio; VFA: Fatty acids; YC: Yeast culture

\section{Acknowledgements}

The first author (GMA) is grateful for scholarship from Chinese Scholarship Council (2016DFHC47)

\section{Funding}

This work was supported by Beijing Agricultural Committee (20160146), Tianjin Commission of Science and Technology (15YFXQNC00020), National Dairy Industry and Technology System (CARS-37) and Key Technologies R\&D Program of China (2012BAD12B06).

Availability of data and materials Not applicable.

\section{Authors' contributions}

GMA carried out the literature review and wrote the draft manuscript; JXX, ZHW, SLL, YJW ZJC, helped in the literature review; All the authors read and approved the final manuscript.

\section{Competing interests}

The authors declare that they have no competing interests.

\section{Consent for publication}

Not applicable.

\section{Ethics approval and consent to participate}

Not applicable.

Received: 4 October 2016 Accepted: 29 March 2017

Published online: 01 May 2017

\section{References}

1. Heinrichs AJ, Heinrichs BS. A prospective study of calf factors affecting first-lactation and lifetime milk production and age of cows when removed from the herd. J Dairy Sci. 2011;94:336-41.

2. Jasper J, Weary DM. Effects of Ad Libitum milk intake on dairy calves. J Dairy Sci. 2002;85:3054-8. doi:10.3168/jds.S0022-0302(02)74391-9.

3. Drackley JK. Calf nutrition from birth to breeding. 2008:24. doi:10.1016/j.cvfa.2008.01.001.

4. Tahmasbi AM, Heidari Jahan Abadi S., Naserian AA. The effect of 2 liquid feeds and 2 sources of protein in starter on performance and blood metabolites in Holstein neonatal calves. J. Dairy Sci.2014;97:363-71.

5. Ontsouka EC, Albrecht C, Bruckmaier RM, Altmann SW, Davis HR, Zhu L, et al. Invited review: growth-promoting effects of colostrum in calves based on interaction with intestinal cell surface receptors and receptor-like transporters. J Dairy Sci. 2016;99:4111-23. doi:10.3168/jds.2015-9741.

6. Khan MA, Bach A, Weary DM, von Keyserlingk MAG. Invited review: transitioning from milk to solid feed in dairy heifers. J Dairy Sci. 2015;99: 885-902. doi:10.3168/jds.2015-9975.

7. Mirzaei M, Khorvash M, Ghorbani GR, Kazemi-Bonchenari M, Ghaffari MH, AOAC, et al. Growth performance, feeding behavior, and selected blood metabolites of Holstein dairy calves fed restricted amounts of milk: No interactions between sources of finely ground grain and forage provision. J Dairy Sci. 2016;0:E55-65. doi:10.3168/jds.2016-11592.

8. Vlková E, Trojanová I, Rada V. Distribution of bifidobacteria in the gastrointestinal tract of calves. Folia Microbiol (Praha). 2006;51:325-8. doi:10.1007/BF02931825.

9. NAHMS. National dairy heifer evaluation project: dairy herd management practices focusing on preweaned heifers. Fort Collins: USDAAPHISVS; 2002.

10. Fey PD, Safranek TJ, Rupp ME, Dunne EF, Ribot E, Iwen PC, et al. Ceftriaxone-resistant salmonella infection acquired by a child from cattle. N Engl J Med. 2000;342:1242-9. doi:10.1056/NEJM200004273421703.

11. Langford FM, Weary DM, Fisher L. Antibiotic resistance in qut bacteria from dairy calves: a dose response to the level of antibiotics fed in milk. J Dairy Sci. 2003;86:3963-6.

12. Martin SA. Manipulation of ruminal fermentation with organic acids: a review. J Anim Sci. 1998;76:3123-32.

13. Witte W. Medical consequences of antibiotic use in agriculture. Science. 1998;279:1996-7.

14. Signorini ML, Soto LP, Zbrun MV, Sequeira GJ, Rosmini MR, Frizzo LS. Impact of probiotic administration on the health and fecal microbiota of young calves: a meta-analysis of randomized controlled trials of lactic acid bacteria. Res Vet Sci. 2012;93:250-8.

15. Eckles $\mathrm{CH}$, Williams VM, Wilbur JW, Palmer LS, Harshaw HM. Yeast as a supplementary feed for calves. J Dairy Sci. 1924;7:421-39. doi:10.3168/jds. S0022-0302(24)94040-9.

16. Kiarie E, Bhandari S, Scott M, Krause D, Nyachoti C. Growth performance and gastrointestinal microbial ecology responses of piglets receiving Saccharomyces cerevisiae fermentation products after an oral challenge with Escherichia coli (K88). J Anim Sci. 2011;89:1062-78.

17. Zaworski EM, Shriver-munsch CM, Fadden NA, Sanchez WK, Yoon I, Bobe G. Effects of feeding various dosages of Saccharomyces cerevisiae fermentation product in transition dairy cows. J Dairy Sci. 2014;97:3081-98. doi:10.3168/jds.2013-7692.

18. Jouany JP, Medina B, Bertin G, Julliand V. Effect of live yeast culture supplementation on hindgut microbial communities and their 
polysaccharidase and glycoside hydrolase activities in horses fed a high-fiber or high-starch diet. J Anim Sci. 2009;87:2844-52

19. Desnoyers M, Giger-Reverdin S, Bertin G, Duvaux-Ponter C, Sauvant D. Metaanalysis of the influence of Saccharomyces cerevisiae supplementation on ruminal parameters and milk production of ruminants. J Dairy Sci. 2009;92: 1620-32. doi:10.3168/jds.2008-1414.

20. Poppy GD, Rabiee AR, Lean IJ, Sanchez WK, Dorton KL, Morley PS. A metaanalysis of the effects of feeding yeast culture produced by anaerobic fermentation of Saccharomyces cerevisiae on milk production of lactating dairy cows. J Dairy Sci. 2012;95:6027-41. doi:10.3168/jds.2012-5577.

21. NRC. Nutrient requirements of dairy cattle, vol. 7th rev. 2001.

22. Lascano GJ, Heinrichs AJ. Yeast culture (Saccharomyces cerevisiae) supplementation in growing animals in the dairy industry. CAB Rev Perspect Agric Vet Sci Nutr Nat Resour. 2007;2:49. doi:10.1079/PAVSNNR20072049.

23. Robinson PH, Erasmus $\sqcup$. Effects of analyzable diet components on responses of lactating dairy cows to Saccharomyces cerevisiae based yeast products: a systematic review of the literature. Anim Feed Sci Technol. 2009; 149:185-98. doi:10.1016/j.anifeedsci.2008.10.003.

24. Zinn RA, Alverez EG, Rogriguez S, Salinas J. Influence of yeast culture on health, performance and digestive function of feedlot steers. Proc West Sect Am Soc Anim Sci. 1999;50:335-8.

25. Brewer MT, Anderson KL, Yoon I, Scott MF, Carlson SA. Amelioration of salmonellosis in pre-weaned dairy calves fed Saccharomyces cerevisiae fermentation products in feed and milk replacer. Vet Microbiol. 2014;172: 248-55. doi:10.1016/j.vetmic.2014.05.026.

26. Harris TL, Liang Y, Sellers MD, Nightingale CR, Sharon KP, Carroll JA, et al. Influences of SmartCare in milk replacer and XPC in calf starter on the performance and health of pre-weaning Holstein calves challenged orally with an opportunistic infectionwith Citrobacter freundii. J Anim Sci/J Dairy Sci. 2015;93/98:E-Suppl-1. http://m.jtmtg.org/abs/t/64251.

27. Lynch H, Martin S. Effects of Saccharomyces cerevisiae culture and Saccharomyces cerevisiae live cells on in vitro mixed ruminal microorganism fermentation. J Dairy Sci. 2002;85:2603-8. doi:10.3168/jds.S0022-0302(02)74345-2.

28. Callaway ES, Martin SA. Effects of a Saccharomyces cerevisiae culture on ruminal bacteria that utilize lactate and digest cellulose. J Dairy Sci. 1997;80: 2035-44. doi:10.3168/jds.S0022-0302(97)76148-4.

29. Jensen GS, Patterson KM, Yoon I. Yeast culture has anti-inflammatory effects and specifically activates NK cells. Comp Immunol Microbiol Infect Dis. 2008; 31:487-500. doi:10.1016/j.cimid.2007.08.005.

30. Kim MH, Seo JK, Yun CH, Kang SJ, Ko JY, Ha JK. Effects of hydrolyzed yeast supplementation in calf starter on immune responses to vaccine challenge in neonatal calves. Animal. 2011;5:953-60. doi:10.1017/S1751731110002673.

31. Fuller R. Probiotics in man and animals. J Appl Bacteriol. 1989;66:365-78. doi:10.1111/j.1365-2672.1989.tb05105.x.

32. Galvao KN, Santos JE, Coscioni A, Villasenor M, Sischo WM, Berge AC. Effect of feeding live yeast products to calves with failure of passive transfer on performance and patterns of antibiotic resistance in fecal Escherichia coli. Reprod Nutr Dev. 2005:45:427-40. doi:10.1051/rnd:2005040.

33. Pinos-Rodríguez JM, Robinson PH, Ortega ME, Berry SL, Mendoza G, Bárcena R. Performance and rumen fermentation of dairy calves supplemented with Saccharomyces cervisiae1077 or Saccharomyces boulardii 1079. Anim Feed Sci Technol. 2008;140:223-32.

34. Quigley JD, Wallis LB, Dowlen HH, Heitmann RN. Sodium bicarbonate and yeast culture effects on ruminal fermentation, growth, and intake in dairy calves. J Dairy Sci. 1992;75:3531-8. doi:10.3168/jds.S0022-0302(92)78129-6.

35. Lesmeister KE, Heinrichs AJ, Gabler MT. Effects of supplemental yeast (Saccharomyces cerevisiae) culture on rumen development, growth characteristics, and blood parameters in neonatal dairy calves. J Dairy Sci. 2004;87:1832-9. doi:10.3168/jds.S0022-0302(04)73340-8.

36. Huuskonen A, Pesonen M. Does yeast (Saccharomyces cerevisiae) supplementation in calf starter modify feed intake and liveweight gain of dairy bull calves? J Anim Feed Sci. 2015;24:295-301.

37. Hučko B, Bampidis VA, Kodeš A, Christodoulou V, Mudřik Z, Poláková K, et al. Rumen fermentation characteristics in pre-weaning calves receiving yeast culture supplements. Czech J Anim Sci. 2009;54:435-42.

38. Seymour W, Nocek MJE, Siciliano-Jones J. Effects of a colostrum substitute and a dietary brewer's yeast on the health and performance of dairy calves. J Dairy Sci. 1995;78:412-20.

39. Panda AK, Singh R, Pathak NN. Effect of dietary inclusion of Saccharomyces cerevisiae on growth performance of crossbred calves. J Appl Anim Res. $1995 ; 7: 195-200$
40. Chaucheyras-Durand F, Walker ND, Bach A. Effects of active dry yeasts on the rumen microbial ecosystem: past, present and future. Anim Feed Sci Technol. 2008;145:5-26. doi:10.1016/j.anifeedsci.2007.04.019.

41. Magalhães VJA, Susca F, Lima FS, Branco AF, Yoon I, Santos JEP. Effect of feeding yeast culture on performance, health, and immunocompetence of dairy calves. J Dairy Sci. 2008;91:1497-09. https://www.ncbi.nlm.nih.gov/ pubmed/18349243.

42. Fallon RJ and BE. The effect of different levels of yeast culture inclusion in the concentrate diet on calf performance. J Dairy Sci. 2001;84:E-Suppl-1. http://apps.webofknowledge.com/full_record.do?product=UA\&search_ mode $=$ GeneralSearch\&qid $=30 \& S I D=Y 1$ b1 IKigS7 wcNczyZAn\&page $=1 \& \mathrm{doc}=4$.

43. Haddad SG, Goussous SN. Effect of yeast culture supplementation on nutrient intake, digestibility and growth performance of Awassi lambs. Anim Feed Sci Technol. 2005;118:343-8. doi:10.1016/j.anifeedsci.2004.10.003.

44. Hill SR, Hopkins BA, Davidson S, Bolt SM, Diaz DE, Brownie C, et al. The addition of cottonseed hulls to the starter and supplementation of live yeast or mannanoligosaccharide in the milk for young calves. J Dairy Sci. 2009;92:790-8.

45. Zhou G, Zhen YG, Yan ZG, Li ZQ, WGH, WKJ. Study on the effects of yeast culture on the digestibility and growing development in calves. J Jilin Anim Husb Veterinanry Med. 2009;30:8-10.

46. Xiao JX, Alugongo GM, Chung R, Dong SZ, Li SL, Yoon I, et al. Effects of Saccharomyces cerevisiae fermentation products on dairy calves: Ruminal fermentation, gastrointestinal morphology, and microbial community. J Dairy Sci. 2016:99:5401-12. doi:10.3168/jds.2015-10563.

47. Agarwal N, Kamra DN, Chaudhary LC, Agarwal I, Sahoo A, Pathak NN. Microbial status and rumen enzyme profile of crossbred calves fed on different microbial feed additives. Lett Appl Microbiol. 2002;34:329-36. doi: 10.1046/j.1472-765X.2002.01092.x

48. Oikonomou G, Teixeira AGV, Foditsch C, Bicalho ML, Machado VS, Bicalho RC. Fecal microbial diversity in pre-weaned dairy calves as described by pyrosequencing of metagenomic $16 \mathrm{~S}$ rDNA. associations of Faecalibacterium species with health and growth. PLoS One 2013;8. doi:10.1371/journal.pone.0063157.

49. Jensen GS, Patterson KM, Yoon I. Nutritional yeast culture has specific antimicrobial properties without affecting healthy flora. Preliminary results. J Anim Feed Sci. 2008;17:247-52.

50. Alugongo GM, Xiao JX, Chung YH, Dong SZ, Li SL, Yoon I, et al. Effects of Saccharomyces cerevisiae fermentation products on dairy calves: performance and health. J Dairy Sci. 2016;0:4707-14. doi:10.3168/jds.2016-11399.

51. Deitch EA, Berg R. Bacterial translocation from the gut: a mechanism of infection. J Burn Care Rehabil. 1987;8:475-82.

52. Araujo G, Yunta C, Terré M, Mereu A, Ipharraguerre I, Bach A. Intestinal permeability and incidence of diarrhea in newborn calves. J Dairy Sci. 2015; 98:7309-17. doi:10.3168/jds.2015-9666.

53. Yan XG, Zhou G, Zhen YG, Chen H, Li ZQ. Effects of yeast culture on rumen development. Chin Dairy Cattle. 2005;5:12-14. http://www.cqvip.com/QK 98003X/200505/20154592.html.

54. Cole NA, Purdy CW, Hutcheson DP. Influence of yeast culture on feeder calves and lambs. J Anim Sci. 1992;70:1682-90.

55. Tripathi MK, Karim SA. Effect of yeast cultures supplementation on live weight change, rumen fermentation, ciliate protozoa population, microbial hydrolytic enzymes status and slaughtering performance of growing lamb. Livest Sci. 2011;135:17-25.

56. Sullivan HM, Martin SA. Effects of a Saccharomyces cerevisiae cuture on in vitro mixed ruminal microorgniams fermentation. J Dairy Sci. 1999;82:2011-6.

57. Auclair $\mathrm{E}$. Yeast as an example of the mode of action of probiotics in monogastric and ruminant species. In: Feed manufacturing in the Mediterranean region. Feed Manuf Mediterr Reg Improv Saf From Feed to Food. 2001;54:45-53.

58. Wójcik R. Effects of brewers' yeast (SC) extract on selected parameters of humoral and cellular immunity in lambs. Bull Vet Inst Pulawy. 2010;54:181-7.

59. Shen YB, Piao XS, Kim SW, Wang L, Liu P, Yoon I, et al. Effects of yeast culture supplementation on growth performance, intestinal health, and immune response of nursery pigs. J Anim Sci. 2009;87:2614-24. doi:10.2527/jas.2008-1512.

60. Weedman S, Rostagno M, Patterson J, Yoon I, Fitzner G, Eicher S. Yeast culture supplement during nursing and transport affects immunity and intestinal microbial ecology of weanling pigs. J Anim Sci. 2011;89:1908-21.

61. Wójcik R. The effect of Leiber Beta-S on selected immunity indicators in calves. Acta Vet Brno. 2014;83:113-8. 
62. Volman JJ, Ramakers JD, Plat J. Dietary modulation of immune function by beta-glucans. Physiol Behav. 2008;94:276-84. doi:10.1016/j.physbeh. 2007.11.045.

63. Wang LJ, Qi CM, Wang JQ, Song TB, Bo L, Shi JJ. Influence of yeast culture on plasma endotoxin concentration of calves study. J Chin Anim Husb Vet Med. 2006:33:19-21.

64. Gerros TC, Semrad SD, Proctor RA. Alterations in clinical, hematological and metabolic variables in bovine neonatal endotoxemia. Can J Vet Res. 1995;59:34-9.

65. Borderas TF, De Passillé AM, Rushen J. Behavior of dairy calves after a low dose of bacterial endotoxin. J Anim Sci. 2008;86:2920-7. doi:10.2527/jas. 2008-0926.

66. Evans $M$, Reeves $S$, Robinson LE. A dried yeast fermentate prevents and reduces inflammation in two separate experimental immune models. Evid Based Complement Altern Med. 2012;2012. doi:10.1155/2012/973041.

67. Nonnecke BJ, Foote MR, Smith JM, Pesch BA, Van Amburgh ME. Composition and functional capacity of blood mononuclear leukocyte populations from neonatal calves on standard and intensified milk replacer diets. J Dairy Sci. 2003; 86:3592-604. doi:10.3168/jds.S0022-0302(03)73965-4.

68. Khan MA, Weary DM, von Keyserlingk MAG. Invited review: effects of milk ration on solid feed intake, weaning, and performance in dairy heifers. J Dairy Sci. 2011;94:1071-81. doi:10.3168/jds.2010-3733.

69. Obeidat BS, Cobb CJ, Sellers MD, Pepper-Yowell R, Earleywine TJ, Ballou M. Plane of nutrition during the preweaning period but not the grower phase influences the neutrophil activity of Holstein calves. J Dairy Sci. 2013;96: 7155-66. doi:10.3168/jds.2013-6699.

70. Ballou MA, Hanson DL, Cobb CJ, Obeidat BS, Sellers MD, Pepper-Yowell AR, et al. Plane of nutrition influences the performance, innate leukocyte responses, and resistance to an oral Salmonella enterica serotype Typhimurium challenge in Jersey calves. J Dairy Sci. 2015;98:1972-82. doi:10.3168/jds.2014-8783.

71. Weaver DM, Tyler JW, VanMetre DC, Hostetler DE, Barrington GM. Passive transfer of colostral immunoglobulins in calves. J Vet Intern Med. 2000;14: 569-77. doi:10.1111/j.1939-1676.2000.tb02278.x.

72. Rauprich ABE, Hammon HM, Blum JW. Influence of feeding different amounts of first colostrum on metabolic, endocrine, and health status and on growth performance in neonatal calves. J Anim Sci. 2000;78:896-908. doi:10.3168/jds.2014-8359.

73. Li R, Connor E, Li C, Baldwin VR, Sparks M. Characterization of the rumen microbiota of pre-ruminant calves using metagenomic tools. Environ Microbiol. 2012;14:129-39. doi:10.1111/j.1462-2920.2011.02543.x.

74. Jami E, Israel A, Kotser A, Mizrahi I. Exploring the bovine rumen bacterial community from birth to adulthood. ISME J. 2013;7:1069-79. doi:10.1038/ ismej.2013.2

75. Ding G, Chang Y, Zhao L, Zhou Z, Ren L, Meng Q. Effect of Saccharomyces cerevisiae on alfalfa nutrient degradation characteristics and rumen microbial populations of steers fed diets with different concentrate-toforage ratios. J Anim Sci Biotechnol. 2014;5:24.

76. Wang JK, Liu JX, Mao HL, Mao HL, Yoon I. Effects of Saccharomyces cerevisiae fermentation product on in vitro fermentation and microbial communities of low-quality forages and mixed. J Anim Sci. 2013;91:3291-8.

77. Kumar U, Sareen VK, Singh S. Effect of Saccharomyces cerevisiae yeast culture supplement on ruminal metabolism in buffalo calves given a high concentrate diet. Anim Prod. 1994:59:209-15.

78. Mutsvangwa T, Edwards IE, Topps JH, Paterson GFM. The effect of dietary inclusion of yeast culture (Yea-Sacc) on patterns of rumen fermentation, food intake and growth of intensively fed bulls. Anim Prod. 1992;55:35-40. doi:10.1017/S0003356100037247.

79. Kehoe SI, Heinrichs AJ, Baumrucker CR, Greger DL. Effects of nucleotide supplementation in milk replacer on small intestinal absorptive capacity in dairy calves. J Dairy Sci. 2008;91:2759-70. doi:10.3168/jds.2007-0751.

80. Hoseinabadi M, Dehghan-Banadaky M, A. Zali. Effect of yeast probiotic (Saccharomyces cerevisiae) inmilk or starter on growth performance, fecal score and rumen parameters of dairy calves. J Dairy Sci. 2013;96:E-Suppl-1. http://www.jtmtg.org/JAM/2013/abstracts/5.pdf.

81. Durand-Chaucheyras F, Fonty G, Bertin G, Théveniot M, Gouet P. Fate of Levucell SC I-1077 yeast additive during digestive transit in lambs. Reprod Nutr Dev. 1998:38:275-80.

82. Baldwin VIRL, McLeod KR, Klotz JL, Heitmann RN. Rumen development, intestinal growth and hepatic metabolism in the Pre- and postweaning ruminant. J Dairy Sci. 2004;87:E55-65. doi:10.3168/jds.S0022-0302(04)70061-2.
83. Stobo IJF, Roy JHB, Gaston HJ. Rumen development in the calf. I. The effect of diets containing different proportions of concentrates to hay on rumen development. Br J Nutr. 1966;20:171-92.

84. Malmuthuge N, Li M, Goonewardene LA, Oba M, Guan LL. Effect of calf starter feeding on gut microbial diversity and expression of genes involved in host immune responses and tight junctions in dairy calves during weaning transition. J Dairy Sci. 2013;96:3189-200. doi:10.3168/jds.2012-6200.

85. Tajima K, Aminov R, Nagamine T. Diet-dependent shifts in the bacterial population of the rumen revealed with real-time PCR. Appl Environ Microbiol. 2001;67:2766-74.

86. Yohe TT, O'Diam KM, Daniels KM. Growth, ruminal measurements, and health characteristics of Holstein bull calves fed an Aspergillus oryzae fermentation extract. J Dairy Sci. 2015;98:6163-75. doi:10.3168/jds.2015-9313.

87. Kaldmäe $H$, Suurmets $H$, Järveots $T$, Suuroja $T$, Kärt $O$. Effects of supplemental yeast (SaccharomycesCerevisiae) culture on rumen development and growth in calves. Akadeemiline Pollumajanduse Selts. 2008;19:19-23.

88. Carroll JA, Ballou MA, Liang Y. L. The digestive system of 1-week-old Jersey calves is well suited to digest, absorb, and incorporate protein and energy into tissue growth even when calves are fed a high plane of milk replacer. J Dairy Sci. 2016;99:1-9.

89. Steele MA, Penner GB, Chaucheyras-Durand F, Guan LL. Development and physiology of the rumen and the lower gut: Targets for improving gut health. J Dairy Sci. 2016:99:4955-66. doi:10.3168/jds.2015-10351.

90. Wang Z, Yu Q. Lactobacillus amylophilus D14 protects tight junction from enteropathogenic bacteria damage in Caco-2 cells. J Dairy Sci. 2015:95:5580-7.

91. Edrington TS, Dowd SE, Farrow RF, Hagevoort GR, Callaway TR, Anderson $\mathrm{RC}$, et al. Development of colonic microbiota as assessed by pyrosequencing in dairy calves fed waste milk. J Dairy Sci. 2012;95:4519-25. doi:10.3168/jds.2011-5119.

92. Fleige S, Preißinger W, Meyer HHD, Pfaffl MW. Lactulose: effect on apoptotic- and immunological-markers in the gastro-intestinal tract of preruminant calves. Vet Med (Praha). 2007:52:437-44

93. Ballou MA. Nutrition and immunity for pre-weaned dairy calves. In: Proc 23rd Tri-State Dairy Nutr Conf Fort Wayne, Indiana, USA, 14-16 April 2014 2014. p. 41-52.

94. Heinrichs AJ, Jones CM, Heinrichs BS. Effects of mannan oligosaccharide or antibiotics in neonatal diets on health and growth of dairy calves. J Dairy Sci. 2003:86:4064-9.

95. Spring P, Wenk C, Dawson KA, Newman KE. The effects of dietary mannanoligosaccharides on cecal parameters and the concentrations of enteric bacteria in the ceca of salmonella-challenged broiler chicks. Poult Sci. 2000;79:205-11. doi:10.1093/ps/79.2.205.

96. Van Diemen PM, Dziva F, Stevens MP, Wallis TS. Identification of enterohemorrhagic Escherichia coli $\mathrm{O} 26: \mathrm{H}$ - genes required for intestinal colonization in calves. Infect Immun. 2005;73:1735-43. doi:10.1128/IAI.73.3.1735-1743.2005

\section{Submit your next manuscript to BioMed Central and we will help you at every step:}

- We accept pre-submission inquiries

- Our selector tool helps you to find the most relevant journal

- We provide round the clock customer support

- Convenient online submission

- Thorough peer review

- Inclusion in PubMed and all major indexing services

- Maximum visibility for your research

Submit your manuscript at www biomedcentral.com/submit
C BioMed Central 